07.2;08.3; 13.1

\title{
Особенности эпитаксиального роста III-N светодиодных гетероструктур на подложках $\mathrm{SiC} / \mathrm{Si}$
}

\author{
(C) Н.А. Черкашин ${ }^{1}$, А.В. Сахаров ${ }^{2}$, А.Е. Николаев ${ }^{2,3}$, В.В. Лундин ${ }^{3}$, С.О. Усов ${ }^{2}$, В.М. Устинов ${ }^{2}$, \\ А.С. Гращенко ${ }^{4}$, С.А. Кукушкин ${ }^{4}$, А.В. Осипов ${ }^{5}$, А.Ф. Цацульников ${ }^{2,}$ \\ ${ }^{1}$ CEMES-CNRS and Université de Toulouse, Toulouse, France \\ ${ }^{2}$ НТЦ микроэлектроники РАН, Санкт-Петербург, Россия \\ ${ }^{3}$ Физико-технический институт им. А.Ф. Иофрфе РАН, Санкт-Петербург, Россия \\ ${ }^{4}$ Институт проблем машиноведения РАН, Санкт-Петербург, Россия \\ ${ }^{5}$ Санкт-Петербургский государственный университет, Санкт-Петербург, Россия \\ `E-mail: andrew@beam.ioffe.ru
}

Поступило в Редакцию 12 апреля 2021г.

В окончательной редакции 29 апреля 2021 r.

Принято к публикации 29 апреля 2021 г.

\begin{abstract}
Светоизлучающие III-N гетероструктуры выращены методом газофазной эпитаксии из металлоорганических соединений на темплейтах (подложках) $\mathrm{SiC} / \mathrm{Si}$ (111), сформированных методом согласованного замещения атомов. Проведены исследования оптических и структурных свойств гетероструктур с целью выявления формирования дефектов в структурах. Показано, что в таких гетероструктурах наблюдаются особенности роста буферного слоя $(\mathrm{Al}, \mathrm{Ga}) \mathrm{N}$, связанные с наличием пор в $\mathrm{Si}$ под интерфейсом $\mathrm{SiC} / \mathrm{Si}$. Использование оптимизированного дизайна буферного слоя позволяет значительно уменьшить плотность дислокаций и сформировать активную область с хорошим структурным качеством.
\end{abstract}

Ключевые слова: нитрид галлия, карбид кремния, кремний, III-N гетероструктура, газофазная эпитаксия из металлоорганических соединений.

DOI: 10.21883/PJTF.2021.15.51227.18827

Развитие технологии источников света на основе III-N светодиодов идет по пути увеличения объемов производства, что приводит к необходимости выращивания эпитаксиальных структур на дешевых подложках кремния большого диаметра. Основной проблемой использования кремниевых подложек для III-N эпитаксии является значительное различие постоянных кристаллической решетки $(16.9 \%)$ и коэффициентов температурного расширения (115\%) этих материалов, приводящее к образованию дефектов. Для повышения структурного качества были использованы различные подходы, такие, например, как использование низкотемпературных вставок AlN [1], сверхрешеток AlN/GaN [2], профилированных подложек [3] или промежуточного слоя $\mathrm{Al}_{2} \mathrm{O}_{3}$ [4]. Однако недостатком перечисленных подходов является усложнение технологии и увеличение времени технологического процесса. В настоящей работе исследовано использование в качестве подложек темплейтов $\mathrm{SiC} / \mathrm{Si}$, coдержащих на поверхности слой $\mathrm{SiC}$, характеризующийся меньшим различием в параметрах кристаллической решетки с $\mathrm{GaN}$. Были изучены особенности выращивания и свойства светодиодных структур InGaN/GaN на $2^{\prime \prime}$ темплейтах $\mathrm{SiC} / \mathrm{Si}(111)$ с толщиной слоя $\mathrm{SiC} \sim 100 \mathrm{~nm}$, сформированных методом согласованного замещения атомов $[5,6]$.

Исследованные структуры были выращены методом газофазной эпитаксии из металлоорганических соединений на установке Aixtron 2000НТ и содержали следующие слои (образующие сложносоставной буферный слой и активную область, включающую $р$-легированные слои): зародышевый слой $\mathrm{AlN}$ толщиной $\sim 300 \mathrm{~nm}$; последовательность слоев $\mathrm{AlGaN} 1-\mathrm{AlGaN} 5$, имеющих постепенно уменьшающееся содержание $\mathrm{Al}$ от $\sim 80 \%$ в $\mathrm{AlGaN1}$ до $\sim 20 \%$ в $\mathrm{AlGaN} 5$, суммарной толщиной $\sim 0.5 \mu \mathrm{m}$; сверхрешетку (SL), состоящую из 22 периодов $\mathrm{GaN}(6 \mathrm{~nm}) / \mathrm{AlGaN}(7 \mathrm{~nm})$; слой $\mathrm{GaN}$ толщиной $1.3 \mu \mathrm{m}$,

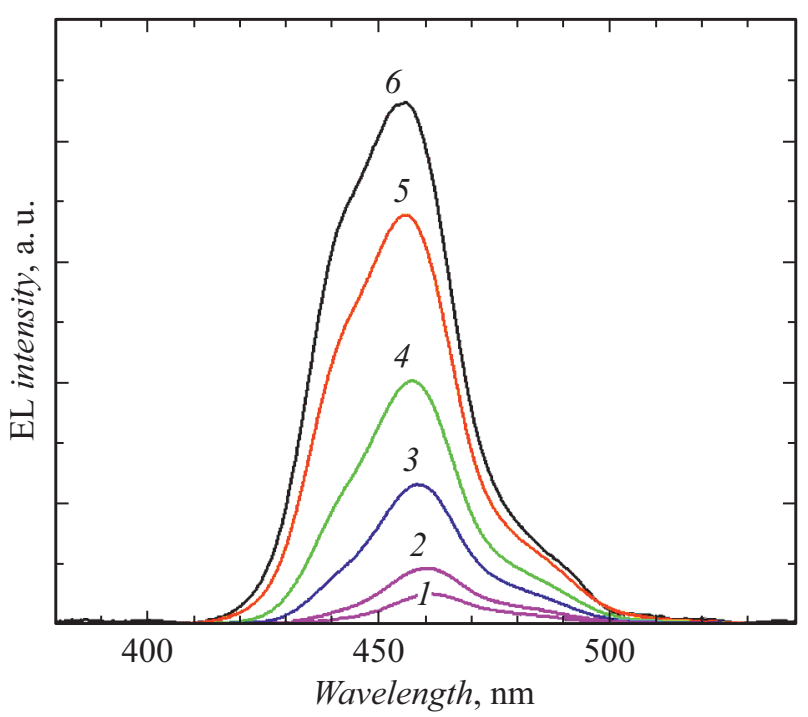

Рис. 1. Спектры электролюминесценции выращенной светодиодной структуры при токах $I=1$ (1), 2 (2), 5 (3), 10 (4), 20 (5) и $30 \mathrm{~mA}(6)$. 


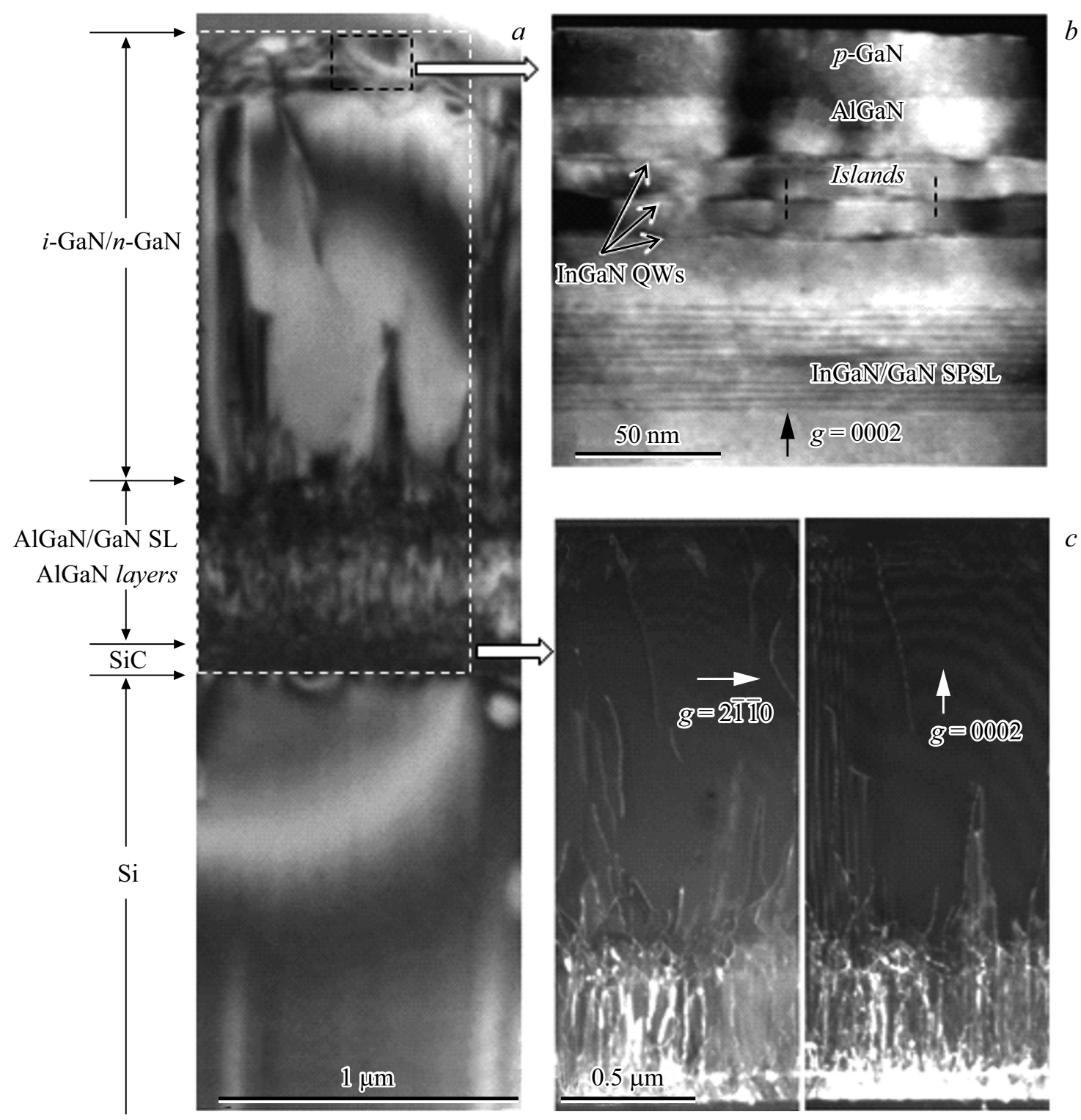

Рис. 2. ПЭМ-изображения поперечного сечения (1010) светодиодной гетероструктуры, выращенной на подложке $\mathrm{SiC} / \mathrm{Si} . a-\mathrm{cвет-}$ лопольное изображение общего вида; $b-$ темнопольное изображение активной области структуры, полученное с $g=0002 ; c-$ темнопольные изображения общего вида, полученные в режиме слабого пучка с дифракционными рефлексами $g=2 \overline{1} \overline{1} 0$ (слева) и $g=0002$ (справа).

легированный кремнием; активную область InGaN/GaN. Суммарная толщина слоев $\mathrm{AlGaN}$ и SL примерно в 2 раза меньше по сравнению с толщиной аналогичной последовательности слоев, используемой при росте на подложках кремния, что демонстрирует возможность уменьшения времени эпитаксиального процесса. Активная область содержала короткопериодную сверхрешетку (SPSL) с 12 периодами InGaN (1 nm)/GaN (1 nm), слой $\mathrm{GaN}$ толщиной $25 \mathrm{~nm}$, последовательность из трех квантовых ям (QW) InGaN шириной $2 \mathrm{~nm}$, разделенных слоями $\mathrm{GaN}$ толщиной $7 \mathrm{~nm}$, блокирующий слой $\mathrm{AlGaN}: \mathrm{Mg}$ толщиной $15 \mathrm{~nm}$ с содержанием Al 15\% и контактный слой $p-\mathrm{GaN}$ толщиной $130 \mathrm{~nm}$.
На рис. 1 приведены спектры светодиодной структуры с использованием полупрозрачного контакта площадью $0.3 \mathrm{~mm}^{2}$. Максимум излучения лежит в синей области спектра с максимальной длиной волны 455-460 nm. Вольт-амперные зависимости в области малых токов (ниже $0.1 \mathrm{~mA}$ ) свидетельствуют о наличии утечек, что может быть обусловлено формированием протяженных дефектов в структуре. Оценка эффективности излучения на пластине затруднена из-за наличия поглощающей свет подложки.

Структурные свойства светодиодных гетероструктур были изучены методом просвечивающей электронной микроскопии (ПЭМ). На рис. 2, $а$ приведено светло- 
$a$

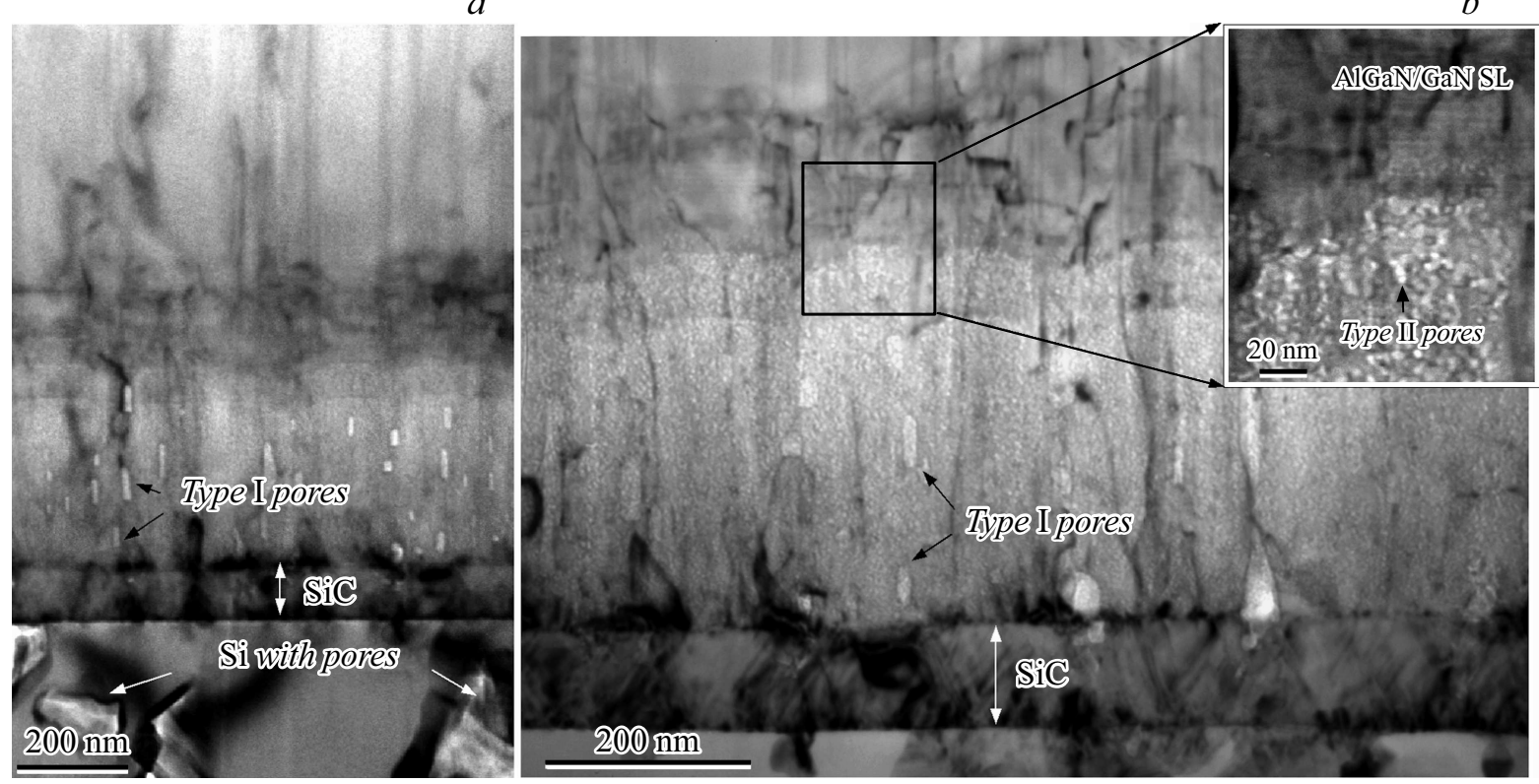

Рис. 3. Светлопольные слегка расфокусированные и вне условий отражений Брэгга ПЭМ-изображения поперечного сечения $(10 \overline{1} 0)$ нижней части выращенной гетероструктуры, полученные при малом $(a)$ и среднем $(b)$ увеличении. На вставке показано увеличенное изображение пор типа II в области сверхрешетки $\mathrm{AlGaN} / \mathrm{GaN}$.

польное ПЭМ-изображение выращенной структуры, полученное в поперечном сечении (1010). Можно выделить принципиально различающиеся по структурному качеству области буферного слоя (рис. 2,c) и активной области (рис. $2, b$ ). Буферный слой состоит из блоков с характерными латеральными размерами от 0.1 до $1 \mu \mathrm{m}$. Большие блоки имеют плоскую поверхность (0001), а самые маленькие блоки характеризуются пирамидальной формой с гранями $\{01 \overline{1} 1\}$ или трапециевидной формой с поверхностью (0001) и гранями $\{01 \overline{1} 1\}$. Была выявлена взаимосвязь между размерами блоков и отсутствием или наличием пор под интерфейсом $\mathrm{SiC} / \mathrm{Si}$ [6]. В областях, где поры отсутствуют, наблюдается рост структуры с плоской (0001) поверхностью. Присутствие пор обусловливает неоднородности в толщине слоя $\mathrm{SiC}$ в диапазоне $20-110 \mathrm{~nm}$, приводит к изменению начальных условий роста $\mathrm{AlGaN}$ и росту блоков меньшего размера [7].

На рис. 2,c приведены темнопольные изображения, полученные в поперечном сечении (1010) в режиме слабого пучка с дифракционными рефлексами $g=2 \overline{1} \overline{1} 0$ (слева) и $g=0002$ (справа). Анализ полученных изображений, снятых в данных условиях [8], позволил оценить плотность дислокаций различного типа (краевых, винтовых и смешанных) в различных областях гетероструктуры. В нижней части гетероструктуры в последовательности слоев $\mathrm{AlGaN}$ различного состава суммарная плотность дислокаций всех типов составляет $\sim 10^{10} \mathrm{~cm}^{-2}$. Использование сверхрешетки $\mathrm{AlGaN} / \mathrm{GaN}$ приводит к уменьшению плотности дислокаций в нижней части слоя $\mathrm{GaN}$ до $\sim 3 \cdot 10^{9} \mathrm{~cm}^{-2}$ (плотность краевых дислокаций составляет $\sim 2.2 \cdot 10^{9} \mathrm{~cm}^{-2}$, плотность винтовых дислокаций составляет $\sim 5 \cdot 10^{8} \mathrm{~cm}^{-2}$, а плотность дислокаций смешанного типа составляет $\sim 4 \cdot 10^{8} \mathrm{~cm}^{-2}$ ). Уменьшение плотности прорастающих дислокаций происходит в результате их загиба в плоскость (0001), вызванного наличием градиента напряжений между слоями $\mathrm{AlGaN} \mathrm{c}$ постепенно уменьшающимся составом по Аl. Плотность краевых дислокаций в активной области (рис. 2,b) составляет $\sim 5 \cdot 10^{8} \mathrm{~cm}^{-2}$, при этом плотность других типов дислокаций сохраняется на уровне соответствующих значений в слое $\mathrm{GaN}$. Таким образом, суммарная плотность дислокаций в активной области совпадает с плотностью дислокаций для подобных структур, выращенных на подложках сапфира.

На рис. 3 показаны светлопольные слегка расфокусированные и вне условий отражений Брэгга изображения, полученные из нижней части структуры. Выбранные условия эксперимента позволяют значительно подавить дифракционный контраст, вызванный дислокациями, и четко визуализировать зоны с различной плотностью атомов. Можно выделить два типа пор (I и II). Поры типа I (рис. $3, a$ ) имеют сильно асимметричную форму с осью, вытянутой вдоль направления [0001]. Их ширина варьируется от 5 до $20 \mathrm{~nm}$, а длина в направлении [0001] — от 10 до $100 \mathrm{~nm}$. Они распределены внутри слоя структуры толщиной $420 \mathrm{~nm}$, включающего слой $\mathrm{SiC}$, и имеют среднюю концентрацию $1.3 \cdot 10^{15} \mathrm{~cm}^{-3}$. Формирование пор этого типа может быть связано либо с влиянием малоугловых границ зерен в $\mathrm{SiC}$ на процесс нуклеации AlN и их рост [7], либо с диффузией $\mathrm{Si}$ и последующим образованием вакансионных пор [9]. 
Поры типа II (вставка на рис. 3, b) имеют намного меньший размер, они не присутствуют в слое $\mathrm{SiC}$ и имеют гораздо более высокую концентрацию в последовательности слоев $\mathrm{AlGaN}$ по сравнению с порами типа I. Они имеют квазисферическую форму с диаметром от 2 до $5 \mathrm{~nm}$, их средняя концентрация в области слоев $\mathrm{AlGaN}$ составляет $\sim 3 \cdot 10^{17} \mathrm{~cm}^{-3}$. Наличие пор может увеличить дефектность структуры, однако возможен оптимальный подбор условий роста $\mathrm{SiC}$, при котором концентрация пор не влияет на рост гетероструктуры, с одновременным уменьшением термических деформаций. С другой стороны, наличие пор позволяет значительно увеличить вывод света (этому вопросу будет посвящена отдельная публикация).

Таким образом, было показано, что поры, образующиеся на границе $\mathrm{SiC} / \mathrm{Si}$, приводят к модификации начальных условий роста гетероструктуры и формированию блоков, имеющих различный латеральный размер в диапазоне $0.1-1 \mu \mathrm{m}$. Помимо пор на границе $\mathrm{SiC} / \mathrm{Si}$ были выявлены поры в буферном слое гетероструктуры. Данные особенности приводят к высокой плотности дислокаций в буферном слое, доминирующими из которых являются краевые дислокации. Плотность дислокаций эффективно может быть уменьшена c $\sim 10^{10}$ до $\sim 3 \cdot 10^{9} \mathrm{~cm}^{-2}$ при использовании сверхрешеток $\mathrm{AlGaN} / \mathrm{GaN}$.

\section{Благодарности}

Синтез пленок $\mathrm{SiC} / \mathrm{Si}$ проводился с использованием оборудования Уникальной научной установки „Физика, химия и механика кристаллов и тонких пленок“ ФГУП ИПМаш РАН (Санкт-Петербург).

\section{Финансирование работы}

А.С. Гращенко и С.А. Кукушкин выполняли свою часть работы при поддержке Министерства науки и высшего образования РФ в рамках государственного задания ФГПУ ИПМаш РАН по контракту № FFNF-2021-0001, А.В. Осипов выполнял свою часть работы при поддержке Министерства науки и высшего образования РФ в рамках государственного задания по контракту СПбГУ № 61520973.

\section{Конфликт интересов}

Авторы заявляют, что у них нет конфликта интересов.

\section{Список литературы}

[1] A. Dadgar, M. Poschenrieder, J. Bläsing, K. Fehse, A. Diez, A. Krost, Appl. Phys. Lett., 80 (20), 3670 (2002). DOI: $10.1063 / 1.1479455$

[2] T. Egawa, T. Moku, H. Ishikawa, K. Ohtsuka, T. Jimbo, Jpn. J. Appl. Phys., 41 (6B), L663 (2002). DOI: 10.1143/JJAP.41.L663
[3] B. Zhang, H. Liang, Y. Wang, Z. Feng, K.W. Ng, K.M. Lau, J. Cryst. Growth., 298, 725 (2007). DOI: $10.1016 /$ j.jcrysgro.2006.10.170

[4] W.E. Fenwick, A. Melton, T. Xu, N. Li, C. Summers, M. Jamil, I.T. Ferguson, Appl. Phys. Lett., 94 (22), 222105 (2009). DOI: $10.1063 / 1.3148328$

[5] С.А. Кукушкин, А.В. Осипов, ФТТ, 50 (7), 1188 (2008). [Пер. версия: 10.1134/S10637834080 70081].

[6] С.А. Кукушкин, А.В. Осипов, Н.А. Феоктистов, ФТТ, 56 (8), 1457 (2014). [Пер. версия: 10.1134/S1063783414080137].

[7] S.A. Kukushkin, Sh.Sh. Sharofidinov, A.V. Osipov, A.V. Redkov, V.V. Kidalov, A.S. Grashchenko, I.P. Soshnikov, A.F. Dydenchuk, ECS J. Solid State Sci. Technol., 7 (9), 480 (2018). DOI: 10.1149/2.0191809jss

[8] V.S. Kopp, V.M. Kaganer, M.V. Baidakova, W.V. Lundin, A.E. Nikolaev, E.V. Verkhovtceva, M.A. Yagovkina, N. Cherkashin, J. Appl. Phys., 115 (7), 073507 (2014). DOI: doi.org/10.1063/1.4865502

[9] Я.Е. Гегузин, Дифбузионная зона (Наука, М., 1979). 